\title{
Semantic similarity influences early morphological priming in Serbian: A challenge to form-then-meaning accounts of word recognition
}

\author{
Laurie Beth Feldman • Aleksandar Kostić • \\ Vasilije Gvozdenović • Patrick A. O'Connor • \\ Fermín Moscoso del Prado Martín
}

Published online: 3 April 2012

(C) Psychonomic Society, Inc. 2012

\begin{abstract}
Semantically similar (e.g., coolant-COOL) primes have produced greater facilitation than have formsimilar but semantically dissimilar (e.g., rampant-RAMP) primes when English words have appeared in the forwardmasked primed lexical decision task (Feldman, O'Connor, \& Moscoso del Prado Martín, Psychonomic Bulletin \& Review 16: 684-691, 2009). These results challenge claims that form-based, semantically blind activation underlies early morphological facilitation. Some have argued that the English materials in previous studies were not ideally constructed, insofar as the types of spelling changes to affixed stems differed in the semantically similar and dissimilar pairs. The present study exploited Serbian's bialphabetism, rich morphology, and homographic (form-identical) stems to replicate early effects of semantic similarity. Furthermore, it incorporated within-target manipulations of prime type
\end{abstract}

L. B. Feldman · P. A. O'Connor

University at Albany, State University of New York,

Albany, NY SS 369, USA

L. B. Feldman $(\bowtie) \cdot$ P. A. O’Connor

Haskins Laboratories,

300 George Street,

New Haven, CT 06511, USA

e-mail: 1feldman@albany.edu

A. Kostić · V. Gvozdenović

Faculty of Philosophy Cika Ljubina, University of Belgrade,

Belgrade, Serbia

F. Moscoso del Prado Martín

CNRS UMR5585, Aix-Marseille Université de Lyon,

Lyon, France

F. Moscoso del Prado Martín

UMR6146 Aix-Marseille Université,

Lyon, France and of alphabet, such that the alphabets of the prime-target pairs matched in Experiment 1a and alternated in Experiment $1 \mathrm{~b}$. Importantly, no letter or phoneme changes occurred between the stems of the primes and targets. These results revealed significant effects of semantic similarity that are comparable with and without alphabet alternation. The semantic effects in Serbian replicated almost exactly those in English (Feldman et al., Psychonomic Bulletin \& Review 16: 684-691, 2009), which suggests that even early in the course of processing, morphemes are units of meaning as well as of form. The results failed to support models of lexical processing that postulate sequential access, first to the morphological form, and then to the semantic aspects of words.

Keywords Forward-masked priming task . Morpho-semantic processing $\cdot$ Morpho-orthographic processing $\cdot$ Morphology $\cdot$ Semantic transparency $\cdot$ Serbian . Form-with-meaning accounts $\cdot$ Word recognition

Theories of word recognition differ as to whether orthographic form and meaning processes occur concurrently and interdependently or sequentially and independently. Trivially, all models of visual recognition assume that a word's orthographic form plays a role in lexical access, so that the letters that make up a word strongly influence its interpretation. At issue is whether there is a stage of form processing that is isolated from semantics, so that it is meaningful to claim that activation of a word form precedes activation of its meaning. If form processing is not autonomous from meaning processing, then form codes can become structured by the contexts in which a word appears, so that form and meaning are not readily isolable. 
Semantic influences on word-level processes have been detected in a variety of recognition tasks, and similar effects arise in spoken recognition with pictures (e.g., Apfelbaum, Blumstein, \& McMurray, 2011) and with written words. In the visual lexical decision task, forward-masked related primes activate targets more than unrelated primes do when semantic relatedness is based on forms, such as LGHT, that are orthographically distorted words (Perea \& Gomez, 2010). Even more relevant, when form overlap is equated, facilitation is greater for morphologically similar (fell-FALL) than for form-similar (fill-FALL) prime-target pairs, in which only the former pairs are similar in meaning (Crepaldi, Rastle, Coltheart, \& Nickels, 2010; Pastizzo \& Feldman, 2002). Findings such as these are consistent with the cascaded activation of a word's semantics before orthographic processing terminates. The present study contrasts form-with-meaning accounts and sequential-form-then-meaning accounts in the context of morphological processing.

Words are morphologically structured if they can be decomposed into multiple meaningful units (morphemes), as is the case with many words in English or Serbian. For instance, segmentation of the affix -ER from WHITER or FARMER leaves stems (WHITE and FARM) that are often, but not always, semantically similar to the original word. Other words, such as CORNER or MOTHER, only appear to be morphologically structured; that is, they have a letter sequence, such as $\mathrm{ER}$, that functions as an affix in many other words, but not in these particular words. At the same time, their meaning is dissimilar to that of the words that are embedded in them (CORN or MOTH). Finally, there are words like CUTER that are composed of a stem and an affix, but the stem CUTE cannot be derived simply by stripping off the -ER affix, because of the stem's similarity to the homographic stem CUT.

When words are composed of multiple morphemes, they are assumed to undergo segmentation into their constituent morphemes in the course of recognition. Accordingly, in a priming task, processing of a morphologically complex prime (i.e., one composed of multiple morphemes) leads to preactivation of its stem in a morphologically related target, and this produces morphological facilitation. When the stimulus onset asynchrony (SOA) is $100 \mathrm{~ms}$ or more, the results of priming studies are difficult to interpret in terms of a single, isolated stage of lexical processing, because it is possible to use the prime to predict the target, so that episodic and other strategic knowledge may contaminate the lexical effects. Consequently, it is often assumed by masked-priming researchers that SOAs longer than $100 \mathrm{~ms}$ do not reveal "early" stages of processing during recognition. When forward-masked primes and SOAs of $50 \mathrm{~ms}$ or less are used, however, interlevel effects are less likely, and it is generally assumed that effects arising with very brief SOAs reflect very early stages of processing.

Traditionally, models of visual recognition assume that word form guides lexical access. The controversy regarding an early role for semantics derives from a subset of morphological-priming studies in which the prime and target always "appear" to be morphologically related, yet they may or may not share meaning. In these priming tasks, it is common to report greater facilitation for semantically similar (e.g., whiter-WHITE) than for semantically dissimilar (e.g., corner-CORN $)^{1}$ prime-target pairs when at least $100 \mathrm{~ms}$ separate the prime and target onsets in the lexical decision task (e.g., Feldman \& Soltano, 1999; MarslenWilson, Tyler, Waksler, \& Older, 1994). Crucially, at shorter SOAs, fewer studies report significantly greater facilitation for semantically similar than for semantically dissimilar pairs, either with (farmer-FARM vs. corner-CORN) or without (pledge-VOW vs. scrape-VOW) shared form. Rastle, Davis, and New (2004) failed to detect a difference between semantically similar and dissimilar pairs that shared form, and Rastle and Davis (2008) summarized other studies that replicated their null effect. Rastle and colleagues interpreted the absence of an effect of semantic similarity in the presence of a form effect as evidence that masked and brief prime presentations tap into form-based processing, where the morpho-orthographic but not the morphosemantic properties of the stem govern morphological facilitation (for a second perspective, see Rueckl \& Aicher, 2008).

Morpho-orthographic refers to effects that arise from the frequent repetition of the orthographic properties of a morpheme (i.e., "act" appears in many words), and morpho-semantic refers to the meaning of a morpheme that persists despite variation in context (i.e., an "actor" is someone who acts; an "action" is the outcome of an act). In essence, in a morphoorthographic process, morphemes are units of form but not of meaning. Elsewhere, we have termed this a form-then-meaning account. Feldman, O'Connor, and Moscoso del Prado Martín (2009) conducted a meta-analysis of Rastle and Davis's (2008) morphological-priming review. Their results raised the possibility of semantic contributions to a purportedly morphoorthographic stage, insofar as facilitation is significantly greater for semantically similar than for dissimilar pairs. The present study provides further documentation of semantic influences concurrent with early formed-based processing - this time in Serbian, a language that features a shallow writing system (i.e., a consistent mapping between grapheme and phoneme) in each of its two alphabets, along with a rich morphology.

Evidence that the degree of similarity between the meanings of morphologically complex primes and their stems influences the magnitudes of facilitation under masked primed presentation conditions in the lexical decision task does not derive from a single experiment or a single metaanalysis. Across a range of SOAs $(32,50,67,87$, and

\footnotetext{
${ }^{1}$ Semantically dissimilar pairs do not qualify as morphologically opaque relatives because they are formed from different, albeit homographic, morphemes.
} 
$100 \mathrm{~ms}$ ) in English, responses have been shown to be faster following semantically similar primes than following dissimilar primes matched for degree of form overlap. Similar results have arisen for both native (Feldman, Moscoso del Prado Martín, \& O'Connor, 2011) and nonnative speakers (Diependaele, Duñabeitia, \& Keuleers, 2011). These findings with different materials replicated Feldman et al. (2009), insofar as semantically similar pairs produced greater facilitation than did semantically dissimilar pairs. Davis and Rastle (2010) claimed that it is "logically possible" for facilitation to reflect both morpho-orthographic and morpho-semantic processing in a single experiment, but that these effects are independent, in that they arise in different brain regions or in different time windows. Davis and Rastle did allow for the possibility that when primes are forward masked, semantic similarity and morpho-orthographic structure might separately contribute to facilitation, but crucially, they failed to grant the possibility that the effects of semantic and form similarity may be interdependent and may inform each other early in the course of a single recognition process. For these researchers, early processing is semantically blind, and when semantic effects have appeared to arise, Davis and Rastle argued that methodological deviations pertaining to the stimulus construction were likely to have produced them (e.g., Feldman et al., 2009). More specifically, Davis and Rastle focused on patterns of orthographic alternations between the semantically similar and dissimilar materials and contended that the dissimilar condition included many prime-target pairs whose orthographic changes were nonsystematic and arbitrary, according to the criteria promulgated by McCormick, Rastle, and Davis (2008).

We sought to replicate the much-contested semantic influences on early morphological processing, but this time in Serbian, a language written in two alphabets, Roman and Cyrillic. Serbian readers are generally fluent in both alphabets. Together with its shallow writing system and consistent grapheme-to-phoneme mappings in each of its two alphabets, Serbian features a rich morphology and many homographic stems. At long lags, when items intervene between the prime and target, the magnitudes of morphological facilitation are comparable whether the prime and the target are visually similar (because the shared morpheme is written in the same alphabet) or are less similar (because the alphabet alternates between prime and target; Feldman \& Moskovljević, 1987). In the present study, we compared facilitation after semantically similar (raved-RAVE) and dissimilar (raven-RAVE) prime-target pairs that appear to have form-identical stems when the affix (viz., -ED) or possible affix (viz., -EN) is removed. Thus, affixes like -ED or -EN function to disambiguate form-identical (or homographic) stems such as RAV(E) into such forms as either RAVED or RAVEN. One consequence is that only when they are semantically similar are targets morphological relatives of the prime. The dissimilar primes in the present study could be pseudo-affixed forms of homographic stems, like ravenRAVE, or affixed forms of a homographic stem, like cuter-CUT.

Importantly, the cuter-CUT example in English violates the preserved phonology constraint, whereas all primetarget pairs in the Serbian materials maintained the spelling and pronunciation of the shared portion. Consistent forms within a pair are important because a small proportion of the materials in the Feldman et al. (2011; Feldman et al., 2009) experiments with English materials included primes and targets with alternations in the spelling or pronunciation of the stem. Examples of such alternations are the dissimilar pairs cabbage-CAB, cavity-CAVE, and palatable-PALACE. However, Feldman et al. (2011; Feldman et al., 2009) did match the numbers of these spelling changes between their semantically dissimilar and similar conditions. Examples of such changes in the similar condition include palatialPALACE, striding-STRIDE, and batter-BAT. Obviously, materials that do not introduce spelling changes between the similar and dissimilar conditions would be preferable.

Finally, the alphabets of the prime and target were manipulated (Roman primes and targets in Exp. 1a; Cyrillic primes and Roman targets in Exp. 1b), so as to reduce the orthographic similarity between prime and target. If effects of semantic similarity were to arise when the prime and target were in different alphabets, and if the effects were comparable to those for pairs with no alphabet change, then morphological facilitation would be less likely to derive from repetition of orthographic structure between prime and target. Also noteworthy is that, across participants, the same target appeared with semantically similar and dissimilar primes, so that target properties would not be confounded between the similar and dissimilar conditions. Feldman and colleagues used different targets between the similar and dissimilar conditions in their earlier work (Feldman et al., 2009) but incorporated a within-target design in later experiments (Feldman et al., 2011). Both studies presented English materials and contained many instances of spelling changes between the prime and target. To anticipate, our results replicated, in Serbian, the early effects of semantics on facilitation when the spelling and pronunciation changes between prime and target that can occur in English were absent.

\section{Method}

Participants

A group of 115 students from the Faculty of Philosophy at the University of Belgrade participated in partial fulfillment of the introductory psychology course requirements. All were native speakers of Serbian with no known reading or 
speech disorders and with normal or corrected-to-normal vision. The national curriculum dictates that all students learn both the Roman and Cyrillic scripts in elementary school, with a 1-year lag in favor of Cyrillic. None of the students participated in both Experiments 1a and $1 \mathrm{~b}$.

\section{Materials}

A total of 60 nominative singular nouns or infinitive verbs were selected as critical word targets. Three prime types (similar, dissimilar, and unrelated) appeared with each target across counterbalancing lists. The Appendix comprises the targets, their English translations, the three primes for each target, and their parses into stem and affix. The unrelated primes were formed from stems that were semantically and orthographically different from their target. In the other two conditions, form similarity was equated. In the semantically similar condition, the meaning of the target (e.g., RAT, meaning war; GLAD, meaning hunger) was preserved in the affixed prime (e.g., RATOVI, meaning wars; GLADAN, meaning hungry), so that members of a pair (ratovi-RAT, gladan-GLAD) were morphologically related by inflection or by derivation. In the semantically dissimilar condition, some of the primes were morphologically simple (e.g., RATAR, meaning peasant; GLADAK, meaning smooth) but ended with a letter sequence (e.g., AR or AK) that functions as an affix in other words. Other semantically dissimilar primes were morphologically complex and formed from stems that were homographic with the target. Both morphologically simple and complex affixed words appeared as unrelated primes, so as to mimic the two related prime types, and these primes contained minimal letter overlap with their targets.

The items for the different prime types were matched on frequency (using frequency counts extracted from Kostić, 1999) and word length in letters (see Table 1). Experimental lists that contain a high proportion of identical (ID) primetarget filler trials (e.g., papir-PAPIR) produce semantic facilitation even when the primes are forward masked (Bodner \& Masson, 2003). Moreover, the inclusion of formsimilar word-word (ID) and word-nonword (quasi-ID) trials to create a relatedness proportion of $75 \%$ significantly boosts semantic and morphological, but not orthographic, facilitation

Table 1 Mean (and standard deviation) log frequencies and lengths for the critical primes and targets used in the present study

\begin{tabular}{lllll}
\hline & \multicolumn{2}{l}{ Prime Type-Semantic Relation } & \\
\cline { 2 - 4 } Attribute & Similar & Dissimilar & Unrelated & Target \\
\hline Length & $5.9(0.9)$ & $6.1(1.3)$ & $5.3(0.9)$ & $4.5(1.4)$ \\
Log frequency & $0.79(0.51)$ & $0.96(0.78)$ & $0.79(0.06)$ & $1.76(0.74)$ \\
\hline
\end{tabular}

(Feldman \& Basnight-Brown, 2008). Therefore, in the present study, as in Feldman et al. (2009), we introduced many ID filler trials and concomitant listwise semantic similarity, so as to maximize morphological facilitation and the potential to detect an interaction with semantic similarity. Finally, as with the word-word pairs, two-thirds of the word-nonword pairs were orthographically similar, and one-third were not. Because we maintained the same ratios of form-similar and dissimilar pairs, form similarity did not predict the lexicality of the target (cf. Rastle et al., 2004).

\section{Design}

Prime type was manipulated within participants, and alphabet was manipulated between participants (i.e., in Exp. 1a, the participants viewed both the prime and target in the Roman alphabet, whereas in Exp. 1b, the participants saw a Cyrillic prime followed by a Roman target). Across participants, all of the targets were preceded by semantically similar, dissimilar, and unrelated primes equally often, and with the exception of one oversight, no target was repeated within a session. In addition to the 60 critical items described above, 30 wordword pairs were included as filler trials. All of the word--word filler pairs had identical primes and targets (i.e., ID trials). One half of these pairs included an affix, and thus were complex. Each participant thus responded to 90 word target trials, of which 70 were similar in form. To parallel the word-word pairs, 70 of the word-nonword pairs contained the nonword target's form plus a frequent letter sequence as the ending on the prime (e.g., pitak-PIT, prazan-PRAZ), and 20 shared no letters in the same position (torbica-KIMEL).

\section{Procedure}

The task was presented on a PC-compatible computer running the Superlab 2 software. Each trial began with a 500-ms fixation mark $(+)$ that appeared in the middle of the screen. An interstimulus interval of $50 \mathrm{~ms}$ occurred before the forward mask (a number of "\#" signs matched to the prime length) that lasted $450 \mathrm{~ms}$. The prime then appeared in lowercase letters for $50 \mathrm{~ms}$ and replaced the mask. The target was printed in uppercase letters and replaced the prime in the same position. The targets were visible for 3,000 $\mathrm{ms}$ or until response, and the intertrial interval was $1,000 \mathrm{~ms}$.

Items were presented in black 16-point Helvetica font (Cyrillic or Roman) on a white background. A different random order of prime-target pairs appeared for each participant. The participants made a lexical decision for each target by pressing the right button (green) on a response box for words and the left button (red) for nonwords. The participants responded to 12 practice trials before the experimental session, and the composition of the practice stimuli mirrored that of the stimuli in the main experiment. 


\section{Results}

Overall, the mean accuracy rates for each participant and each item on critical trials were computed. All of the participants had error rates lower than $30 \%$, and hence no participant's data were discarded. Experiment $1 \mathrm{~b}$ was conducted after the completion of Experiment 1a, and both experiments were collapsed together into two single analyses (one for reaction times [henceforth, RTs] and another for errors). The RT analyses include only correct responses. One item, PAR, appeared twice in each session of Experiment $1 \mathrm{~b}$ due to a programming error and was deleted from all analyses.

The median correct RTs were 714, 674, and $689 \mathrm{~ms}$ for the unrelated, similar, and dissimilar conditions, respectively. In order to approximate the preconditions of a Gaussian linear model (i.e., normality and homoscedasticity), the correct RTs where transformed using the changed-sign reciprocal transform of the RTs in milliseconds (i.e., -1,000/RT). This transformation was chosen by maximum-likelihood estimates of the best Box-Cox transformation for the particular regression models (Box \& Cox, 1964). Linear mixed-effect models (cf. Baayen, Davidson, \& Bates, 2008) were fitted to the transformed RTs with a fixed effect of prime type (similar, dissimilar, or unrelated; coded as contrasts with the unrelated condition, which was mapped onto the intercept) and random effects of targets and participants. The significance of the fixed-effect coefficients was evaluated by sampling 10,000 instances of the model using a Markov-chain Monte Carlo technique. Neither the effect of alphabet (mixed vs. Roman) nor the interaction of alphabet by prime type was significant, so these predictors were not retained in the final model. In order to explicitly test the contrast between the semantically similar and dissimilar pairs, an additional (separate) model was fit, including only the data points in these two conditions. Both linear mixed-effect models were subjected to model criticism by examining the distribution of the model residuals using quantile-quantile plots against a theoretical standard normal. These evaluations showed that the residuals within both models were almost exactly normally distributed, with just two possible outlier trials that deviated from normality. Refitting the models excluding these points did not modify the results. Furthermore, we fitted additional models considering the possibility of mixed-effect interactions between either participant or target item identity and the experimental condition. The model comparison (both using chi-squared loglikelihood tests and the Bayesian information criterion) indicated that neither of these interactions sufficiently improved the model as to justify including them in the final model. The largest absolute-value correlation between the fixed effects in the final model was $.51 .^{2}$

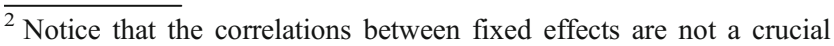
issue in orthogonal designs such as this one. We nevertheless report them, to adhere to reporting standards.
}

The upper panel of Table 2 summarizes the significant fixed effects of the RT models. To summarize, unrelated trials were slower than both dissimilar and similar trials (by reversing the reciprocal transformation, one can estimate the effect sizes to be $25 \mathrm{~ms}$ for the dissimilar vs. unrelated and about $40 \mathrm{~ms}$ for similar vs. unrelated conditions). In this restricted model (restricted to include only those factors that were significant), the correlation between the fixed effects was .19. The bottom of Table 2 reports the explicit comparison between the similar and dissimilar pairs, which was also significant (as one would expect, back-transformation from the reciprocal scale revealed that this difference was $15 \mathrm{~ms}$ ).

The accuracy data were analyzed using logistic mixedeffect model regression. As with RTs, neither the effect of alphabet change nor its interaction with the effect of prime type reached significance. Thus, both were dropped from the models. Similarly, model comparisons failed to provide evidence of mixed-effect interactions between prime type and participant or item identity. The maximum absolute value of the correlation between fixed effects in this model was .50. As can be seen in the top of Table 3, the similar trials elicited significantly fewer errors than did the unrelated trials (about $2.1 \%$ fewer), whereas no significant difference arose between the dissimilar and unrelated trials. The maximum absolute value of the correlations between fixed effects in this model was .50. The bottom section of Table 3 shows a model whose results confirm that the difference in the number of errors between unrelated and similar trials was significantly smaller (about $2.8 \%$ ) than that between unrelated and dissimilar trials. The correlation between the fixed effects in this model was .27 .

\section{Discussion}

In summary, semantically similar primes produced greater facilitation than did semantically dissimilar primes in the

Table 2 Results of linear mixed-effects modeling for reaction times (RTs) when comparing the semantically similar (Sim) and dissimilar (Dis) conditions to each other and to the unrelated (UR) condition, combining Experiments $1 \mathrm{a}$ and $1 \mathrm{~b}$

\begin{tabular}{lllll}
\hline $\begin{array}{l}\text { Overall } \\
\text { Model RTs }\end{array}$ & Estimate & $\begin{array}{l}\text { MCMC } \\
\text { Mean } \\
\\
\text { Estimate }\end{array}$ & HPD 95 \% CI & $p$ (MCMC) \\
\hline Intercept (UR) & -1.3987 & -1.3992 & {$[-1.4343,-1.3605]$} & .0001 \\
Sim vs. UR & -0.0837 & -0.0837 & {$[-0.1000,-0.0679]$} & .0001 \\
Dis vs. UR & -0.0515 & -0.0516 & {$[-0.0685,-0.0360]$} & .0001 \\
Sim vs. Dis & & & & \\
Intercept (Sim) & 1.4823 & -1.4834 & {$[-1.5212,-1.4450]$} & .0001 \\
Sim vs. Dis & 0.0315 & 0.0313 & {$[0.0147,0.0475]$} & .0001 \\
\hline
\end{tabular}

MCMC, Markov-chain Monte Carlo. 
Table 3 Results of linear mixed-effects modeling for error rates when comparing the semantically similar (Sim) and dissimilar (Dis) conditions to each other and to the unrelated (UR) condition, combining Experiments $1 \mathrm{a}$ and $1 \mathrm{~b}$

\begin{tabular}{lllll}
\hline Overall Model Errors & Estimate & Standard Error & $z$ Value & $\operatorname{Pr}(>\mid z)$ \\
\hline Intercept (UR) & 2.4785 & 0.21093 & 11.751 & .0001 \\
Sim vs. UR & 0.3315 & 0.10551 & 3.142 & .0017 \\
Dis vs. UR & -0.1069 & 0.09977 & -1.072 & .2839 \\
Sim vs. Dis & & & & \\
Intercept (Sim) & 2.8347 & 0.2223 & 12.749 & .0001 \\
Sim vs. Dis & -0.4384 & 0.1031 & -4.253 & .0001 \\
\hline
\end{tabular}

forward-masked priming task in Serbian. This difference was not due to differing orthographic similarity between the prime and target induced by using a single or multiple alphabets. In addition, it was not influenced by the contributions of orthographic similarity being greater for the similar primes, because form similarity was equated between semantically similar and dissimilar pairs. Although semantic similarity effects tend to be small numerically, the results of the present study with inflectionally rich Serbian, like those of Feldman et al. (2009) with relatively impoverished English, show very early effects of semantics under conditions that are purported to foster morpho-orthographic but not morpho-semantic processing. In this respect, both studies confirm statistically a pattern that is present in the literature as a whole, albeit not uniformly significant in individual studies. Furthermore, even the estimated magnitude of the effect is consistent with the magnitude reported by Feldman et al. (2009) for English.

The novel contribution of the present study is to demonstrate effects of semantic similarity when primes are forward masked and briefly presented and when the same targets are paired with semantically similar and dissimilar primes. This replication makes it implausible that uncontrolled properties of the dissimilar targets were responsible for the effects of transparency reported in Feldman et al.'s (2009) earlier study, as had been hypothesized by Davis and Rastle (2010).

A secondary novel finding is that any reduction of shared orthographic form due to manipulations of prime-target alphabet did not significantly reduce the effect of semantic transparency (13 vs.16 ms). If one assumed that early morphological priming is caused by form overlap, one might have expected facilitation to be greater when the alphabet did not change from prime to target. However, crossalphabet comparisons failed to support any explicit role of orthographic form.

Letter sequences that behaved in a semantically systematic manner in the prime and target were easier and faster to categorize as words than were those that were inconsistent. The similar and dissimilar primes shared orthographically defined stems and differed only with respect to affixes. Therefore, it is unlikely that the mechanism that underlies morphological facilitation entails that the stem of a morphologically complex or pseudocomplex prime, decomposed and isolated from its affix, preactivates the target (Rastle et al., 2004). Rather, differences between our similar and dissimilar primes could only arise if stem processing is not independent of affix processing. This outcome in a priming paradigm complements reported interactions of affix and stem processes in singleword recognition (e.g., Baayen, Milin, Filipović Durdević, Hendrix, \& Marelli, 2011). Evidently, even at very brief SOAs, morphological processing is not restricted to the product of form-based segmentation - that is, traditional "affixstripping" - so as to segment the stem from the whole word. Rather, processing makes contact with a stem's combinatorial behavior, defined with respect to the morpheme and the word contexts in which it appears.

Here and elsewhere, it has often been asserted that the masked priming paradigm taps "early" phases of processing because the primes appear very briefly and participants are not consciously aware of them. Demarcating early from late processing in this priming task would only be compelling, however, if the recognition system were to stop processing the prime when the target appears. If prime and target can be processed concurrently, then a distinction between early and late processes becomes more difficult to defend. Nonetheless, with brief SOAs and masked primes, we have demonstrated a semantic influence on what others have claimed is a purely form-based stage of processing. We prefer to characterize the semantic and morphological influences on orthographic structure in terms of long-term usage patterns for stems and words across varied contexts, and we assume that words that appear in similar contexts are similar in meaning. For example, FARMER and FARM co-occur more systematically than do words with equal letter overlap, such as CORNER and CORN, and this alters their orthographic processing. Thus, in the present experiments and in others, semantic similarity allows semantically similar primes (e.g., farmerFARM) to benefit target processing in a way that dissimilar primes (e.g., corner-CORN) cannot. We acknowledge, nonetheless, that other accounts of semantics may handle our data as well. More contentious is whether some variant of a model with separate orthographic and semantic levels and cascaded activation between them constitutes a viable option.

The results of the present study, although limited to a single SOA in a single language, reveal cascaded activation of a word's semantics before orthographic processing terminates. With respect to morphological processing, what is certain is that the results are consistent with claims (e.g., Moscoso del Prado Martín, 2007; Plaut \& Gonnerman, 2000) that morphemes are units of meaning as well as units of form, so that morpho-orthographic and morpho-semantic 
processes are not independent and sequential. Our results are also consistent with neurophysiological evidence that has shown near-simultaneous access to the orthographic and semantic aspects of the "neural assembly" that is associated with a word (see, e.g., Pulvermüller, 1999). In conclusion, our- findings contribute to a growing literature challenging the universality of the form-then-meaning assumption within models of "early" word recognition.

Author note The research reported here was supported by funds from National Institute of Child Health and Development Grant HD01994 to Haskins Laboratories and by funds from the Ministry of Science and Education of the Republic of Serbia, Contract \#179033.

\section{Appendix}

Table 4 Critical prime and target pairs presented in the study. (() indicates no affix.)

\begin{tabular}{|c|c|c|c|c|c|c|c|c|}
\hline \multicolumn{3}{|l|}{ Target } & \multicolumn{2}{|l|}{ Similar Prime } & \multicolumn{2}{|c|}{ Dissimilar Prime } & \multicolumn{2}{|c|}{ Unrelated Prime } \\
\hline Whole Word & Stem + Affix & Translation & Whole Word & Stem + Affix & Whole Word & Stem + Affix & Whole Word & Stem + Affix \\
\hline CAR & car & tzar & carem & car-em & carina & carin-a & kvaka & kvak-a \\
\hline ČIN & čin & rank & činom & čin-om & činima & čini-ma & veslo & vesl-o \\
\hline CRV & crv & worm & crvom & crv-om & crven & crven- 0 & ovca & ovc-a \\
\hline ČVOR & čvor & knot & čvorovi & čvor-ovi & čvorak & čvorak-0 & tigar & tigar-0 \\
\hline DAN & dan & day & danu & dan-u & danak & danak-0 & čoban & čoban-0 \\
\hline DOB & dob & age & dobom & dob-om & dobar & dobar-0 & hladan & hlad-an \\
\hline DRUG & drug & friend & drugovi & drug-ovi & drugima & drug-ima & pramac & pramac- 0 \\
\hline GAS & gas & gas & gasovi & gas-ovi & gasim & gasi-m & levak & levak-0 \\
\hline GLAD & glad & hunger & gladan & glad-an & gladak & glad-ak & stablo & stablo-0 \\
\hline GRB & grb & coat of arms & grbovi & grb-ovi & grbav & grb-av & detlić & detlić-0 \\
\hline GRM & grm & bush & grmu & grm-u & grmi & grmi-0 & dleto & dlet-o \\
\hline HRAM & hram & temple & hramu & hram-u & hramati & hrama-ti & pismo & pism-o \\
\hline IZNOS & iznos & amount & iznosom & iznos-om & iznosim & iznos-im & javor & javor-0 \\
\hline JAVITI & javi-ti & to call up & javim & javi-m & javan & javan-0 & palata & palat-a \\
\hline KANTA & kant-a & bucket & kantu & kant-u & kantar & kantar-0 & kruška & krušk-a \\
\hline KIP & kip & statue & kipovi & kip-ovi & kipim & kip-im & jabuka & jabuk-a \\
\hline KLAS & klas & blade of wheat & klasje & klas-je & klase & klas-e & pepeo & pepeo-0 \\
\hline KLIP & klip & piston & klipu & klip-u & klipan & klipan-0 & maska & mask-a \\
\hline KLJUČ & ključ & key & ključem & ključ-em & ključati & ključa-ti & miris & miris-0 \\
\hline LAVA & lav-a & lava & lavi & lav-i & lavovi & lav-ovi & kofer & kofer-0 \\
\hline $\mathrm{LOZ}$ & loz & lottery ticket & lozovi & loz-ovi & loze & loz-e & bič & bič-0 \\
\hline MALJ & malj & hammer & maljem & malj-em & malje & malj-e & ograda & ograd-a \\
\hline MRK & mrk & dark & mrkom & mrk-om & mrkva & mrkv-a & crep & crep-0 \\
\hline MUTITI & muti-ti & to muddy, to smear & mutim & muti-m & mutav & mut-av & pevanje & peva-nje \\
\hline MUZA & muz-a & muse & muzom & muz-om & muzem & muze-m & limun & limun-0 \\
\hline NARAV & narav & temper & naravi & narav-i & naravno & narav-no & lovor & lovor-0 \\
\hline NASTAVA & nastav-a & lectures & nastavu & natav-u & nastavak & nastav-ak & maslac & maslac-0 \\
\hline NOS & nos & nose & nosem & nos-em & nosim & nosi-m & pena & pen-a \\
\hline ODELO & odel-o & suit & odel-om & odel-om & odeliti & odeli-ti & glas & glas-0 \\
\hline ORGAN & organ & organ & organ-i & organ-i & organista & organi-sta & prolaz & prolaz-0 \\
\hline PAR & par & pair & par-ovi & par-ovi & pare & par-e & stadion & stadion- 0 \\
\hline PITATI & pita-ti & to ask & pita-m & pita-m & pitu & pit-u & sumrak & sumrak-0 \\
\hline PLAVITI & plavi-ti & to flood & plavi-š & plavi-šs & plavom & plav-om & lanac & lanac- 0 \\
\hline POJATA & pojat-a & hut & pojat-om & pojat-om & pojati & poja-ti & rovac & rovac- 0 \\
\hline POKORA & pokor-a & penance & pokor-u & pokor-u & pokoran & pokor-an & lakom & lakom-0 \\
\hline POMOR & pomor & apocalypse & pomo-ru & pomor-u & pomorac & pomor-ac & ohol & ohol-0 \\
\hline
\end{tabular}


Table 4 (continued)

\begin{tabular}{|c|c|c|c|c|c|c|c|c|}
\hline \multicolumn{3}{|l|}{ Target } & \multicolumn{2}{|l|}{ Similar Prime } & \multicolumn{2}{|c|}{ Dissimilar Prime } & \multicolumn{2}{|c|}{ Unrelated Prime } \\
\hline Whole Word & Stem + Affix & Translation & Whole Word & Stem + Affix & Whole Word & Stem + Affix & Whole Word & Stem + Affix \\
\hline POREDITI & poredi-ti & to compare & poredi-m & poredi-m & poredak & pored-ak & krigla & krigl-a \\
\hline POSADA & posad-a & crew & posad-u & posad-u & posadim & posadi-m & ogledalo & ogledal-o \\
\hline POSTAVA & postav-a & lining & postav-u & postav-u & postavim & postavi-m & razum & razum-0 \\
\hline POSUDA & posud-a & vessel & posud-om & posud-om & posudim & posudi-m & biser & biser-0 \\
\hline POTEZ & potez & stroke & potez-om & potez-om & potezati & poteza-ti & safir & safir-0 \\
\hline POVOD & povod & cause, motive & povod-u & povod-u & povodac & povod-ac & uzlet & uzlet-0 \\
\hline PRAVA & prav-a & straight line & prav-oj & prav-oj & pravite & pravi-te & zamor & zamor-0 \\
\hline PRAZNIK & praznik & holiday & praznik-u & praznik-u & praznina & praznina & kolač & kolač-0 \\
\hline PROJEKT & projekt & project & projekt-u & projekt-u & projektor & projektor-0 & sestra & sestr-a \\
\hline PROTEZA & protez-a & artificial limb & protez-u & protez-u & protezati & proteza-ti & kafana & kafan-a \\
\hline PUST & pust & wasted, deserted & pustom & pust-om & pustim & pusti-m & brat & brat- 0 \\
\hline RANA & ran-a & wound & ranama & ran-ama & ranog & ran-og & čizma & čizm-a \\
\hline RAT & rat & war & ratovi & rat-ovi & ratar & rat-ar & kanal & kanal-0 \\
\hline RAZRED & razred & class & razredu & razred-u & razrediti & razredi-ti & balvan & balvan-0 \\
\hline RED & red & order & redom & red-om & redak & redak & prsten & prsten- 0 \\
\hline REP & rep & tail & repom & rep-om & repama & rep-ama & film & film-0 \\
\hline REZ & rez & cut & rezom & rez-om & rezak & rez-ak & korpa & korpk-a \\
\hline ROD & rod & gender & rodovi & rod-ovi & rodama & rod-ama & bulka & bulk-a \\
\hline RUM & rum & rum & rumom & rum-om & rumen & rumen-0 & plaža & plaž-a \\
\hline RUŽ & ruž & lipstick & ružem & ruž-em & ružama & ruž-ama & žamor & žamor-0 \\
\hline SIT & sit & fed up & sitog & sit-og & sitan & sitan-0 & buka & buk-a \\
\hline STAJA & staj-a & barn & stajama & staj-ama & stajati & staja-ti & malina & malin-a \\
\hline TON & ton & tone & tonovi & ton-ovi & tonem & tone-m & konopac & konopac-0 \\
\hline VRAT & vrat & neck & vratu & vrat-u & vratima & vrat-ima & domar & dom-ar-0 \\
\hline
\end{tabular}

\section{References}

Apfelbaum, K. S., Blumstein, S. E., \& McMurray, B. (2011). Semantic priming is affected by real-time phonological competition: Evidence for continuous cascading systems. Psychonomic Bulletin \& Review, 141-149. doi:10.3758/s13423-010-0039-8

Baayen, R. H., Davidson, D. J., \& Bates, D. M. (2008). Mixed-effects modeling with crossed random effects for subjects and items. Journal of Memory and Language, 59, 390-412. doi:10.1016/j. jml.2007.12.005

Baayen, R. H., Milin, P., Filipović Durdević, D., Hendrix, P., \& Marelli, M. (2011). An amorphous model for morphological processing in visual comprehension based on naive discriminative learning. Psychological Review, 118, 438-481.

Bodner, G. E., \& Masson, M. E. J. (2003). Beyond spreading activation: An influence of relatedness proportion on masked semantic priming. Psychonomic Bulletin \& Review, 10, 645-652. doi:10.3758/BF03196527

Box, G. E. P., \& Cox, D. R. (1964). An analysis of transformations (with discussion). Journal of the Royal Statistical Society: Series $B, 26,211-252$.

Crepaldi, D., Rastle, K., Coltheart, M., \& Nickels, L. (2010). "Fell" primes "fall", but does "bell" prime "ball"? Masked priming with irregularly-inflected primes. Journal of Memory and Language, 63, 83-99. doi:10.1016/j.jml.2010.03.002

Davis, M. H., \& Rastle, K. (2010). Form and meaning in early morphological processing: Comment on Feldman, O'Connor, and
Moscoso del Prado Martín (2009). Psychonomic Bulletin \& Review, 17, 749-755. doi:10.3758/PBR.17.5.749

Diependaele, K., Duñabeitia, J. A., Morris, J., \& Keuleers, E. (2011). Fast morphological effects in first and second language word recognition. Journal of Memory and Language, 64, 344-358. doi:10.1016/j.jml.2011.01.003

Feldman, L. B., \& Basnight-Brown, D. B. (2008). List context fosters semantic processing: Parallels between semantic and morphological facilitation when primes are forward masked. Journal of Experimental Psychology: Learning, Memory, and Cognition, 34, 680-687.

Feldman, L. B., Moscoso del Prado Martín, F., \& O'Connor, P. A. (2011). Must analysis of meaning follow analysis of form? A time course analysis. Manuscript under review.

Feldman, L. B., \& Moskovljević, J. (1987). Repetition priming is not purely episodic in origin. Journal of Experimental Psychology: Learning, Memory, and Cognition, 13, 573-581.

Feldman, L. B., O’Connor, P. A., del Prado, M., \& Martín, F. (2009). Early morphological processing is morphosemantic and not simply morpho-orthographic: A violation of form-then-meaning accounts of word recognition. Psychonomic Bulletin \& Review, 16, 684-691. doi:10.3758/PBR.16.4.684

Feldman, L. B., \& Soltano, E. G. (1999). Morphological priming: The role of prime duration, semantic transparency and affix position. Brain and Language, 68, 33-39. doi:10.1006/brln.1999.2077

Kostić, D. (1999). Frekvencijski recnik savremenog srpskog jezika ("Frequency dictionary of contemporary Serbian language"). Institute for Experimental Phonetics and Speech Pathology \& 
Laboratory of Experimental Psychology, University of Belgrade, Serbia. Retrieved from www.serbian-corpus.edu.rs

Marslen-Wilson, W., Tyler, L. K., Waksler, R., \& Older, L. (1994). Morphology and meaning in the English mental lexicon. Psychological Review, 101, 3-33. doi:10.1037/0033295X.101.1.3

McCormick, S. F., Rastle, K., \& Davis, M. H. (2008). Is there a "fete" in "fetish"? Effects of orthographic opacity on morphoorthographic segmentation in visual word recognition. Journal of Memory and Language, 58, 307-326. doi:10.1016/j. jm1.2007.05.006

Moscoso del Prado Martín, F. (2007). Co-occurrence and the effect of inflectional paradigms. Lingua e Linguaggio, 6, 247-262.

Pastizzo, M. J., \& Feldman, L. B. (2002). Discrepancies between orthographic and unrelated baselines in masked priming undermine a decompositional account of morphological facilitation. Journal of Experimental Psychology: Learning, Memory, and Cognition, 28, 244-249.
Perea, M., \& Gomez, P. (2010). Does LGHT prime DARK? Masked associative priming with addition neighbors. Memory \& Cognition, 38, 513-518. doi:10.3758/MC.38.4.513

Plaut, D. C., \& Gonnerman, L. M. (2000). Are non-semantic morphological effects incompatible with a distributed connectionist approach to lexical processing? Language \& Cognitive Processes, $15,445-485$.

Pulvermüller, F. (1999). Words in the brain's language. The Behavioral and Brain Sciences, 22, 253-279.

Rastle, K., \& Davis, M. H. (2008). Morphological decomposition based on the analysis of orthography. Language \& Cognitive Processes, 23, 942-971. doi:10.1080/01690960802069730

Rastle, K., Davis, M. H., \& New, B. (2004). The broth in my brother's brothel: Morpho-orthographic segmentation in visual word recognition. Psychonomic Bulletin \& Review, 11, 1090-1098. doi:10.3758/BF03196742

Rueckl, J. G., \& Aicher, K. A. (2008). Are CORNER and BROTHER morphologically complex? Not in the long term. Language \& Cognitive Processes, 23, 972-1001. 